\title{
COR BILOCULARE
}

\author{
BY \\ MAURICE CAMPBELL, FRANCES GARDNER, AND GEOFFREY REYNOLDS
}

From the Cardiac Departments, Guy's Hospital and the Royal Free Hospital

Received September 21, 1951

The heart with only two chambers, the cor biloculare, is rare and the following case that was fully investigated in life seems worth reporting.

D. O. (Case O136), aged 5 years at the time of his death, was the youngest of three brothers of whom the other two are well. His mental development was normal and he was talking by 18 months, but his physical development was slow for he did not walk till 30 months and was always below normal size $-2 \mathrm{ft} .10 \mathrm{in}$. in height and $24 \mathrm{lb}$. in weight at 3 years, and $3 \mathrm{ft} .2 \mathrm{in}$. in height and $34 \mathrm{lb}$. in weight at 5 years.

He was seen by us when 3 years old (1948) and at frequent intervals from then until his death two years later; as there was no great change in his condition, the notes of the different visits have been combined. He was a puny child with rather frequent attacks of bronchitis. His chest was deformed, the left side being prominent and the lower half of the sternum bent sharply backwards.

He was much disabled and breathlessness prevented him walking more than 25 yards. There was no history of squatting. Cyanosis had been present since birth, slight at first but increasing a little during his last two years; there was only slight clubbing of the fingers. Corresponding with these findings, his polycythæmia was only moderate but had been increasing, his hæmoglobin having risen from 118 to 139 per cent shortly before his death, with 8.7 million red cells and a hæmatocrit of 73 per cent.

A continuous murmur that sounded rather superficial was heard over the upper left chest especially in the first and second spaces in front, in the left axilla, and over the left but not over the right side behind. The thrill was fine and only systolic. The second sound in the pulmonary area was loud and single. His blood pressure varied between 90/50 and 105/75.

The heart was moderately enlarged and rather horizontal with a cardio-thoracic ratio of 57 per cent $(9 \cdot 5 / 16.8 \mathrm{~cm}$.) (Fig. 1A). It was sabot-shaped with a fairly deep pulmonary bay that was made less obvious by the very broad pedicle. The right ventricle was much enlarged, though less prominent in the left oblique view than is usual in Fallot's tetralogy because of the anterior position of the aorta: the left ventricle also was thought to be enlarged. The aorta arched normally to the left side: it pulsated forcibly and it was wide and uncoiled so that a truncus arteriosus was thought probable at one time, but later a left pulmonary artery was certainly seen, and probably a smaller right, though these were rather hidden in films because of the shape of the heart : their origin was not seen.

The electrocardiogram appeared to show right ventricular preponderance and this was confirmed by chest leads, $R$ in V1 being nearly $40 \mathrm{~mm}$. with an insignificant $S$, and $R$ remaining of moderate size till V5 (Fig. 2). There was no T inversion beyond V1 where it was only slight. There was a variable pacemaker, $P$ in leads II and III often being small and inverted, and at times there was a change to nodal rhythm, with $P$ just after $Q R S$ with very little change of rate. In one record there was some S-T elevation, probably caused by a variable degree of anoxæmia.

Although the heart was in its normal position on the left, the stomach was found to be on the 317 


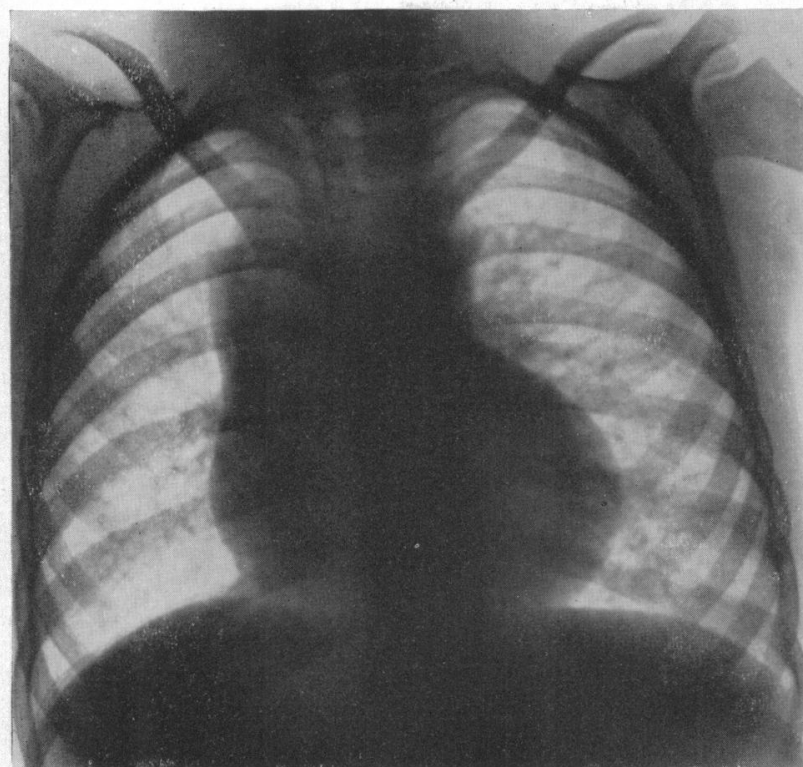

A

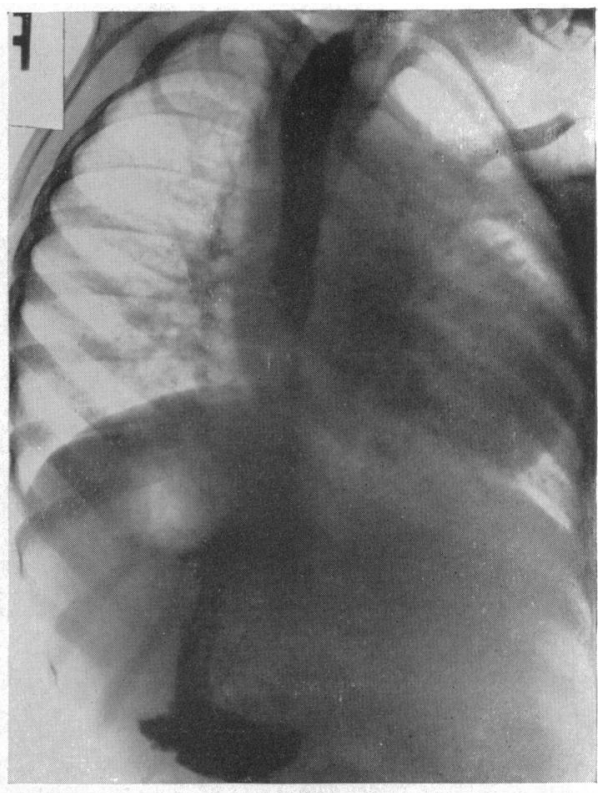

B

Fig. 1.-Teleradiogram from this patient with cor biloculare. (A) shows a moderately large sabot-shaped heart. The extremely wide pedicle was composed of a very horizontally placed aorta and bilateral superior venæ cavæ, one of which was joined by a large azygos vein. (B) Right anterior oblique position. The barium shows the stomach to be on the right, and there was lævocardia with situs inversus of the abdominal viscera.

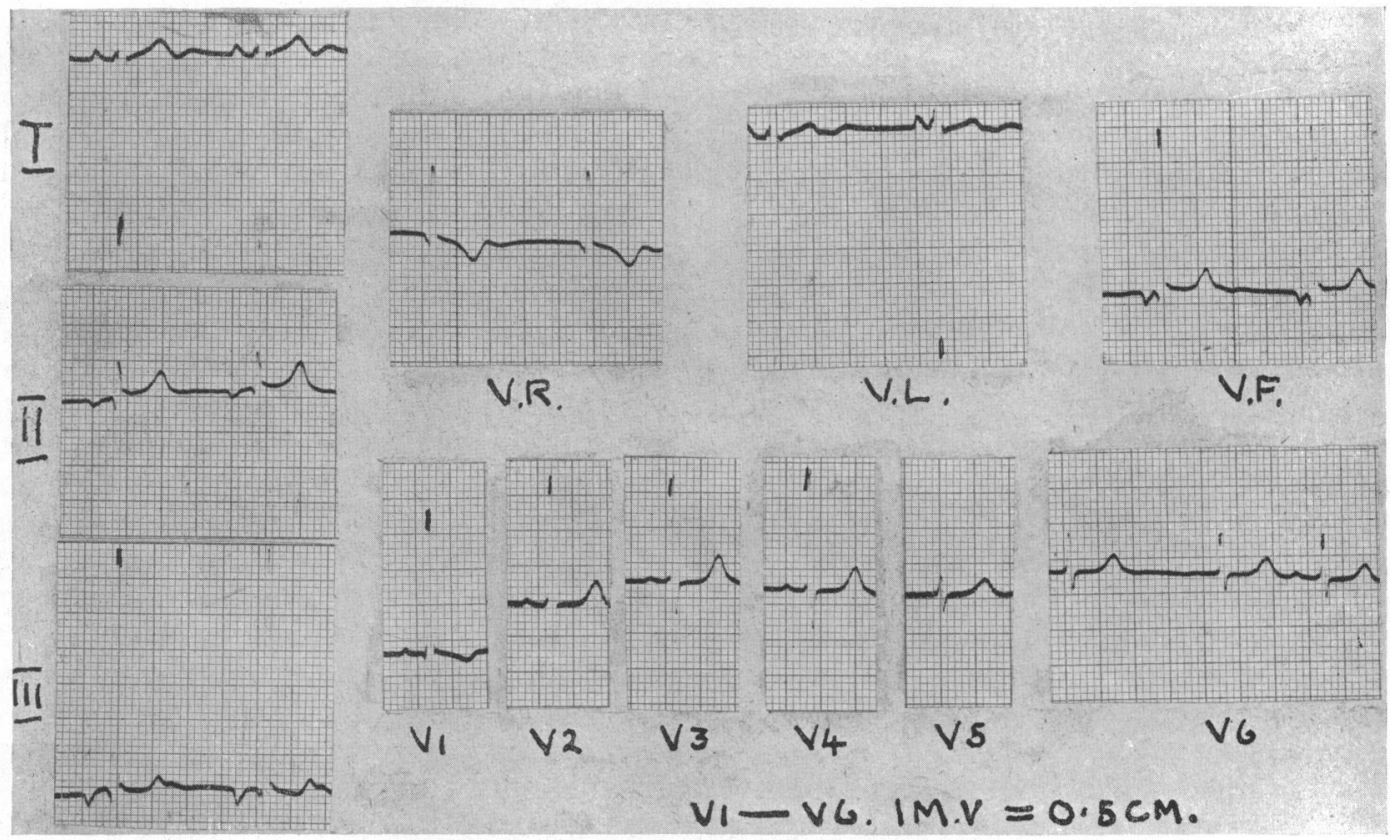

Fig. 2.-Electrocardiogram from this patient with a single ventricle. It appears to show all the features of right ventricular preponderance-gross right axis deviation, a large $R$ in VR, a vertical heart, a large $R$ of $40 \mathrm{~mm}$. and an insignificant $S$ in V1 and $R$ remaining larger than $S$ all across to V6, but becoming small in V5 and V6. Standardization $1 \mathrm{mv} .=0.5 \mathrm{~cm}$. for chest leads. Where they are very fine the tips of the waves have been marked. 
right (Fig. 1B) and the liver on the left side, so that it was likely that the defect of the heart would be complex. The clinical diagnosis was pulmonary atresia with the blood supply to the lungs through bronchial or other collateral arteries that anastomosed with the small pulmonary arteries beyond the atresia. There were no signs of congestive failure.

Angiocardiography. An atrium and ventricle on the right filled readily and at $1 \frac{1}{4}$ sec. the aorta and its branches were already well filled (Fig. 4). At $2 \frac{1}{4} \mathrm{sec}$. the heart shadows were already fading, the aorta was very dense, and both pulmonary arteries, especially the left, were seen fairly well though how they were filling was not obvious (Fig. 3B). At $3 \frac{1}{4} \mathrm{sec}$. the lungs were filling, the left better than the right, and the pulmonary arteries were now as dense as anything else. From then on the shadows only changed slowly and the left side of the heart was not seen to fill again from the pulmonary veins.

Cardiac catheterization. This proved difficult and neither from the left nor from the right arm could the catheter be passed further than the right and left innominate veins, samples from which had an $\mathrm{O}_{2}$ saturation of 54 compared with 63 per cent in the femoral artery.

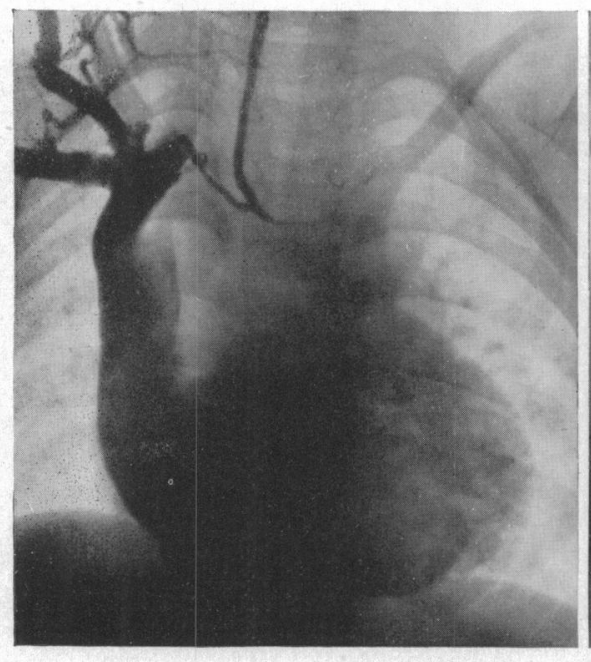

A

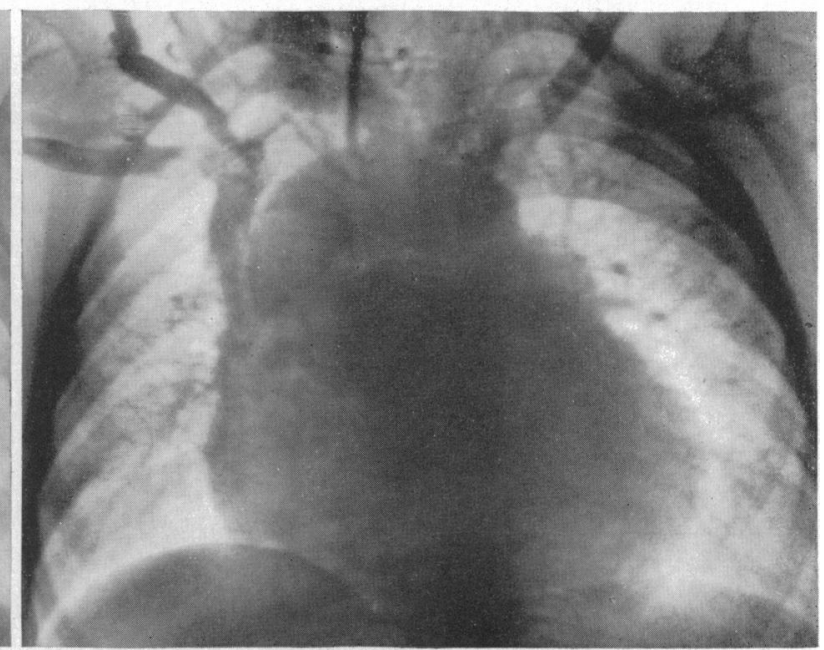

B

Fig. 3.-Angiocardiograms showing the unusual filling of the heart and the very horizontal aorta. (A) At $\frac{3}{4}$ sec. the diodone is mostly on the right and spreading across to the left. The absence of a sharp border to the "right " ventricle might have suggested a single ventricle (see also Fig. 4). At $1 \frac{1}{4}$ sec. the aorta was well filled and this is shown in Fig. 4 where the diodone had been injected from below. (B) At $2 \frac{1}{4}$ sec. the heart shadows have begun to fade, but the aorta is still well seen. The pulmonary arteries, especially the left, are beginning to show but how they are filling is not clear.

Finally the internal saphenous vein was used. The catheter passed straight up past the heart and turned down into the superior vena cava to enter an atrium on the right. Evidently it had passed up a large azygos vein (see Fig. 4)-a vessel that is better known as a collateral channel when the inferior vena cava is obstructed than as a congenital abnormality carrying most of the blood from the lower part of the body.

The samples that were supposed to be from the atrium were, in fact, from the azygos vein. The blood from the ventricle was much more oxygenated $(68-70 \%)$ than that from the azygos vein $(40-44 \%)$ or that taken on an earlier occasion from the jugular vein $(54 \%)$, suggesting that there was also a left-to-right shunt through a ventricular septal defect. The mean pressure in the ventricle was $60 \mathrm{~mm}$. Hg. The pulmonary artery was not entered. Estimations on separate occasions suggested a peripheral flow of 5.2 litres a minute and a pulmonary flow of 1.5 litres but the circumstances were too different to allow any conclusions about the size of the right-to-left shunt. 
Because of the abnormality of the veins, diodone was injected with the catheter in the azygos vein. The atrium filled only through the azygos vein (Fig. 4), which took its normal course although it was performing nearly all of the functions of the inferior vena cava. The hepatic veins, however, did join the atrium in the normal site, as was shown by their filling by backward flow from the atrium at $1 \mathrm{sec}$. (Fig. 4) but not earlier from the azygos vein.

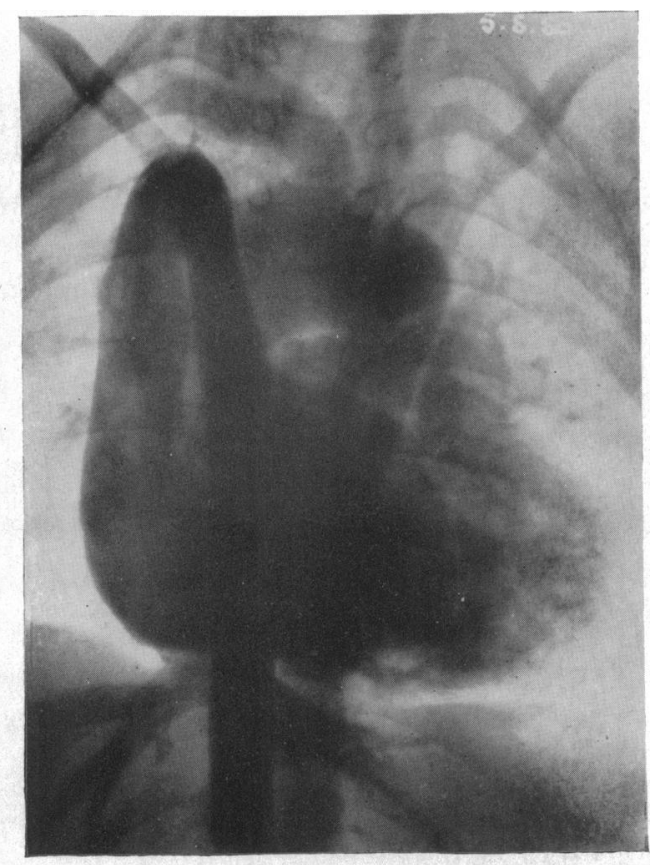

FIG. 4.-Angiocardiogram after injection into the azygos vein. Diodone is seen passing up the azygos vein to enter the superior vena cava which appeared to be the only venous route to the heart from the lower part of the body. After 1 sec., the right side of the heart was well filled and diodone was passing across towards the left side and filling the horizontally placed aorta. The descending aorta is about the same size as the azygos vein. The hepatic veins have filled from the atrium on the right.

Course and operation. The final diagnosis was pulmonary atresia with a large ventricular septal defect. Pulmonary arteries were thought to be present beyond the atresia but it was not certain how they were supplied. The visible pulsation in the neck and in the aorta on radioscopy favoured a patent ductus arteriosus but no pulsation was seen in the pulmonary arteries: the superficial quality of the continuous murmur favoured bronchial arteries though neither the dense diffuse shadows high in the mediastinum nor the nodular shadows at the hilum of the lung that are characteristic of this blood supply to the lungs were seen (Campbell and Gardner, 1950). There was also an azygos vein draining most of the lower part of the body.

It was thought that the blood flow to his lungs was diminished, and that the child would, therefore, benefit by a Blalock-Taussig operation. On July 29, 1950, Mr. R. C. Brock did an end-toend subclavian-pulmonary anastomosis, and found that there was pulmonary atresia and a patent ductus arteriosus with a thrill in the left pulmonary artery just below it. After the operation the patient's colour improved, but he took a long time coming round from the anæsthetic and remained unusually drowsy. Next morning he seemed better, but died suddenly.

\section{Post-Mortem Findings}

Cor biloculare; single atrium; common $A-V$ orifice; single ventricle. Pulmonary trunk atresic, but right and left pulmonary arteries supplied by a patent ductus arteriosus on the left side. Aorta arising from common ventricle without a rudimentary chamber. Absent inferior vena cava. Large azygos vein draining the lower part of the body. Persistent bilateral superior vence cava, the right receiving the azygos vein, and the left entering the atrium through the coronary sinus. 
The azygos vein entered the superior vena cava on the right side in its normal position; it was formed by the junction of the common iliac veins and received all those tributaries that normally join the inferior vena cava, ${ }^{*}$ except the hepatic vein which alone entered the atrium in the normal position. A left superior vena cava was also present, and entered the atrium through a greatly dilated coronary sinus. These changes explained the broad pedicle of the heart. There were no venous valves except a probable remnant of the sinus septum over the coronary sinus. The pulmonary veins from each lung joined into one vein and the two veins, one from the right and one from the left lung, entered the common atrium close together.

The heart weighed $180 \mathrm{~g}$. (Fig. 5). There was a single atrium (Fig. 6). This had a vertical

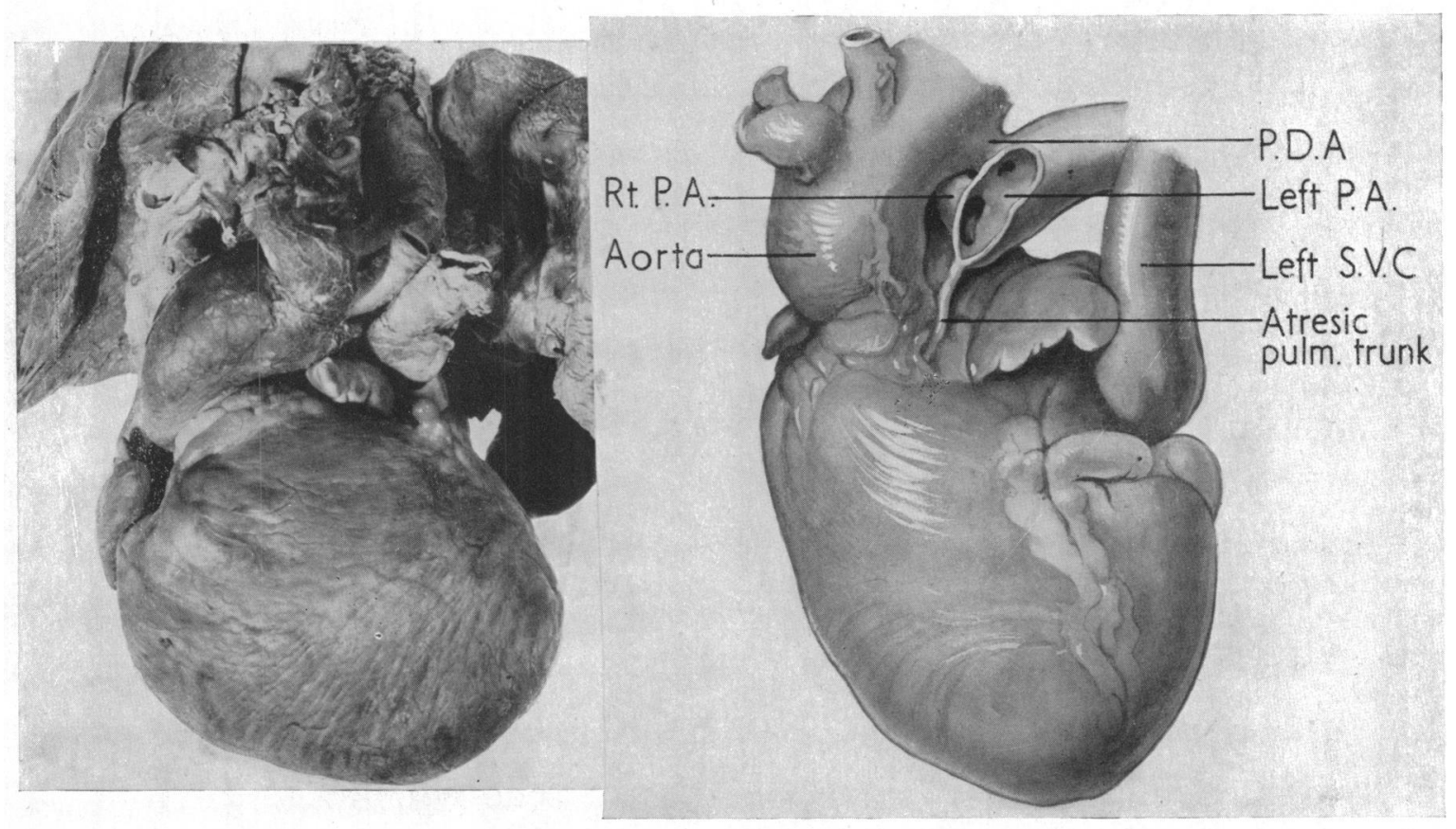

A

B

FIG. 5.- The heart and main vessels. In the photograph (A) the lungs and descending aorta have been turned upwards. The wide rather horizontal position of the aortic arch is well shown. The pulmonary artery is not visible as it is behind the aorta. The curious linear arrangement of the muscle fibres spreading out fanwise from the upper left border is well shown. In the drawing (B) the arrangement of the main vessels can be seen more clearly and they have been spread out for this purpose.

ridge on its superior and anterior walls; Professor Whillis kindly examined the heart with us and thought that it neither looked nor felt like a septum primum but was probably a remnant of the septum spurium. This ridge ended opposite the middle of the common atrioventricular orifice.

The common atrium communicated with the common ventricle through a single, rather oval valve that was $20 \mathrm{~mm}$. in its longest diameter. When the cusps are abnormally formed it may be difficult to decide how many there are, but here the valve had a somewhat rectangular shape suggestive of four valve cusps, though these were not well demarcated from each other and the chordæ tendineæ were not arranged in four separate insertions. There was only one commissure, lying below the left auricular appendage.

There was a single ventricle with no trace of any muscular septum though there were many trabeculæ. It was rather globular in shape and with a raised apex. The superficial muscle fibres

* We have recently seen another patient where cardiac catheterization demonstrated this abnormality. 


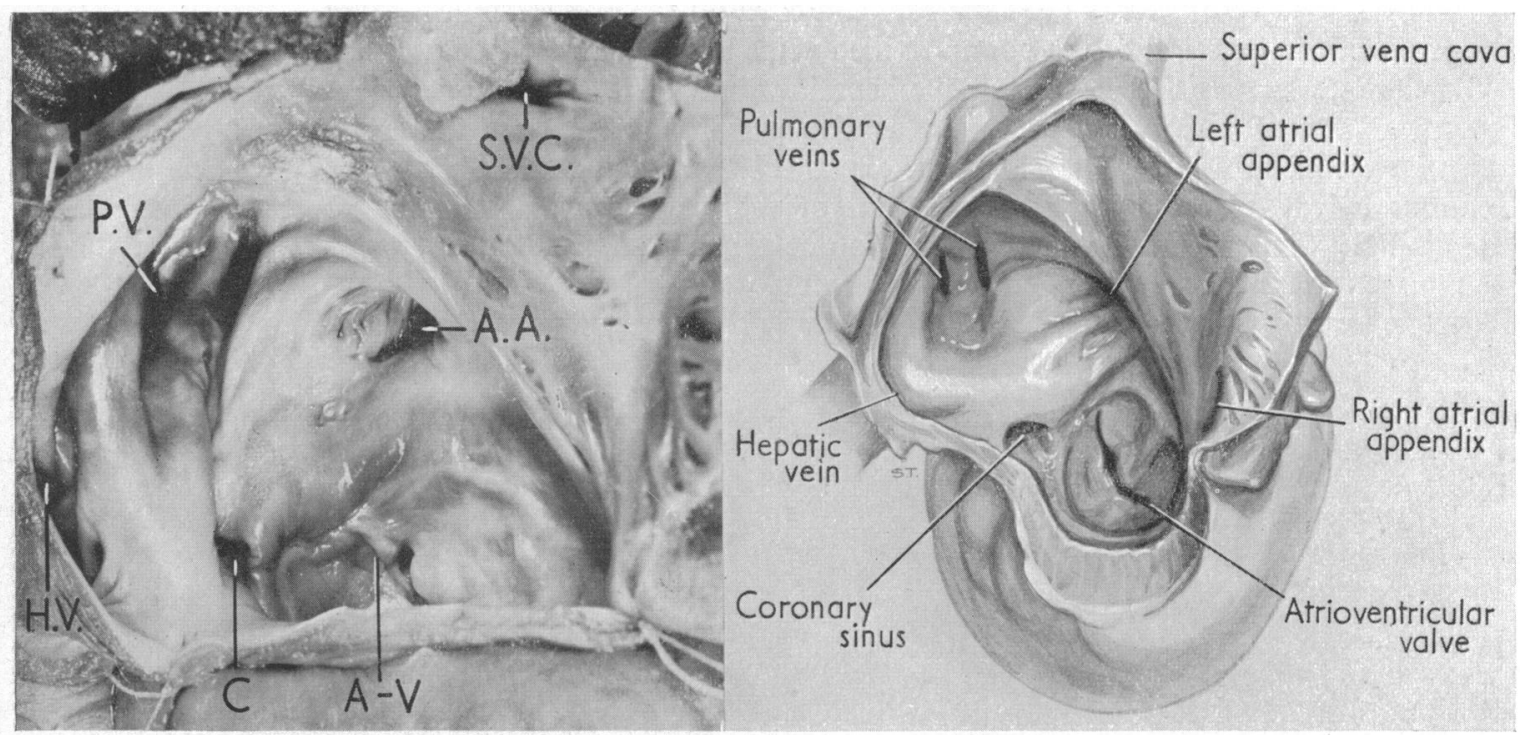

A

B

FIG. 6.-The common atrium has been opened and its walls turned back so that the openings into it can be seen. In the photograph (A) the letters stand for the openings marked on the drawing (B).

fanned out in a curious manner across the anterior surface of the ventricle from its left border, those near the apex running circularly and those nearer the base turning up towards the atrioventricular junction (Fig. 5). The ventricular wall varied in thickness, being $12 \mathrm{~mm}$. anteriorly, $8 \mathrm{~mm}$. at the apex, and $6 \mathrm{~mm}$. posteriorly. One raised band of muscle lay beneath the left border of the anterior wall and another lay between the atrioventricular and aortic valves (Fig. 7).

The aortic valve was normal with two anterior cusps and one posterior cusp; the orifice was $12 \mathrm{~mm}$. in diameter. The large aorta $(30 \mathrm{~mm}$. in diameter) was the only vessel leaving the heart. A small dimple, immediately to the left of the aortic valve, marked the site of the pulmonary trunk; this was atresic throughout its length, but the right and left pulmonary arteries were widely patent the left $(8 \mathrm{~mm}$.) being considerably larger than the right $(5 \mathrm{~mm}$.). A patent ductus arteriosus, $7 \mathrm{~mm}$. long and $4 \mathrm{~mm}$. in internal diameter, opened into the left pulmonary artery near its origin. Just distal to its aortic orifice was a well marked semilunar ridge.

The left coronary artery arose from the left anterior sinus and the right coronary from the posterior sinus. Their distribution was normal. The vessels from the arch of the aorta arose normally:

No gross cerebral lesion was revealed. There was a mild purulent bronchitis. The stomach was in the right side of the abdomen, as was the spleen, which was composed of four separate lobes with other small bodies of splenic tissue lying along the splenic vessels. The liver was central without its shape indicating whether it also was transposed, but its peritoneal attachments showed that this was so.

\section{Discussion}

Cases of congenital heart disease with a single ventricle are not very uncommon. More rarely, a single ventricle may be associated with a single atrium - the true cor biloculare which is one of the most primitive types of cardiac defect. Abbott (1936) included 14 examples among her 1000 cases.

In cor biloculare there is a common A-V orifice and valve, sometimes with the four primitive cusps: there are often other defects as well. Abnormalities of the pulmonary veins are often found 


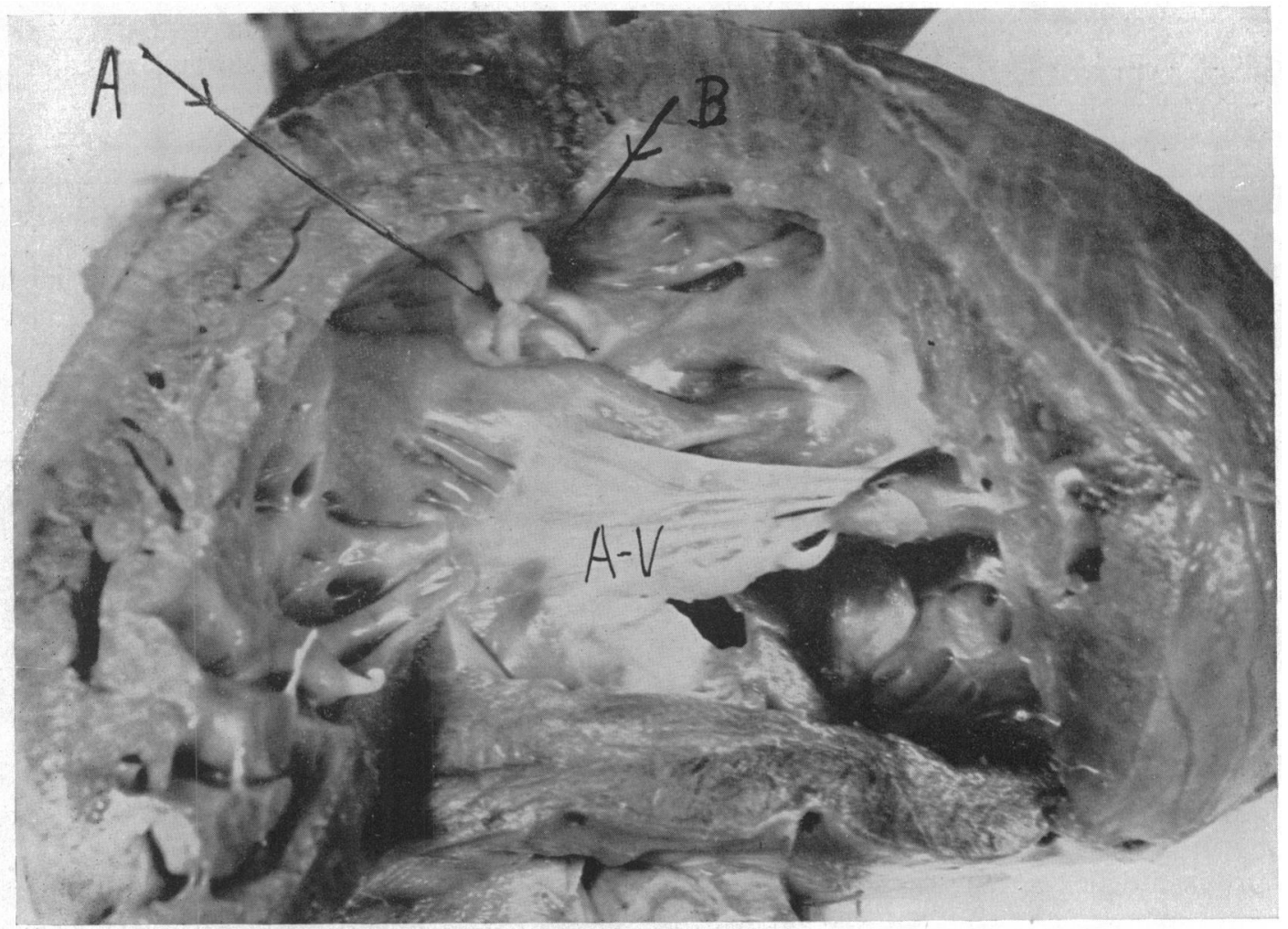

FIG. 7.-The single ventricle has been opened by an incision the direction of which lay between its long axis and the vertical line, and the two halves have been opened out to show the interior. The apex lies to the right. Near the top of the cavity the opening of the aorta can be seen (A); it was not obstructed but the valve flaps have protruded downwards in opening up the heart. In the dark shadow just to the right (B) a dimple was all that represented the site where the pulmonary artery should have opened. Two muscle strands can be seen crossing the heart horizontally, the upper perhaps representing the crista supraventricularis. Below this a single cusp of the common A-V valve can be seen.

with gross defects of the atrial septum, and a truncus arteriosus that has not divided into an aorta and pulmonary trunk is often found with a single ventricle, because embryologically the division of these two parts takes place at the same time. The bilocular heart is, therefore, often associated with both these abnormalities, and with a persistent left superior vena cava, this last because the original more symmetrical arrangement on the sinus venosus has been maintained.

Brown (1950) states that the true bilocular heart is rare and that most of the reported cases are partial examples, often with other abnormalities as well. He divides them into (1) complete forms with an undivided truncus arteriosus, (2) complete forms with the aorta and pulmonary trunk divided and (3) incomplete forms where there is some septal formation but a persistent common A-V valve. This case is an example of his type (2).

The common A-V valve is an essential feature of the true bilocular heart, but also occurs with moderate division of the atria or ventricles or of both as the persistent ostium atrioventriculare commune. Half of the forty reported cases of this defect have occurred in mongols. Evans (1950) has, however, pointed out that a large variety of congenital heart defects occur in mongols, this abnormality being relatively uncommon.

Some of the reported cases of cor biloculare show interesting parallels to our case. Kugel (1932) reported one where there was a partial situs inversus of the abdominal viscera, a common A-V orifice with four cusps, atresia of the pulmonary trunk which arose behind the aorta, 
pulmonary arteries that were supplied through a patent ductus arteriosus, but with a right-sided aortic arch, and an anomaly of the pulmonary veins which in this case entered the atrium on the left by a common trunk.

The case of Rossman (1942) was very similar. The heart was on the left but there was situs inversus of the stomach and liver with incomplete rotation of the intestine: there was agenesis of the spleen and spina bifida. The superior and inferior venæ cavæ entered a single atrium by a common opening and there were two pulmonary veins. The single A-V orifice had four cusps, one large and three small. The aorta and pulmonary trunk were thought to be transposed in position but the latter was only a fibrous remnant and the pulmonary arteries were supplied through a patent ductus. There was a rudimentary muscular ventricular septum.

Taussig (1947) describes two cases. In one (p. 295) there were two A-V orifices, which is unusual, and the rudimentary chamber in the single ventricle was separated by a muscular ridge; the aorta and pulmonary trunk both arose from this but were partly transposed, i.e. the aorta arose in front: the spleen was absent. In her second (p. 510) the patient had dextrocardia with situs inversus; the aorta and pulmonary artery both arose from a single ventricle and there was pulmonary stenosis: it is interesting for comparison with our case that the inferior vena cava could not be traced to the heart, and the hepatic veins entered the atrium separately but near the pulmonary veins.

In the case of Shechter and Meranze (1944) the heart was on the right but the viscera were not transposed. There was a single atrium with two appendages, a single A-V orifice with three cusps, two large and one small. A large pulmonary trunk and, to the right of this, a much smaller aorta which was joined by a large patent ductus arteriosus arose from the single ventricle.

Nelson and Wells (1948) described a patient who lived 27 years: post-mortem, there was almost complete situs inversus, a spleen that was made up of two lobes, a bilocular heart with a common A-V orifice (with two valve cusps), and transposition of the aorta and pulmonary trunk; there was, however, a rudimentary chamber in the left lateral wall of the ventricle, but neither of the great arteries arose from it. The case of Popjak (1942) showed a common A-V orifice with four cusps, a solitary aortic trunk, and right and left pulmonary arteries supplied through a patent ductus. That of Bembenista (1946) showed a small pulmonary artery arising from a rudimentary chamber that was almost isolated from the main chamber, so that the blood supply to the lungs was mainly through the patent ductus.

Although, in our case, a correct diagnosis of some of the anatomical abnormalities was made, cor biloculare was not thought of. A single ventricle might have been suspected because of the absence of any sharp border of the right ventricle in the angiocardiograms and the way in which the diodone passed across to the left (see Fig. 4); but the left to right shunt at this site did not help greatly as this is fairly common with Fallot's tetralogy. The special problem raised by the heart remaining on the left when the abdominal viscera are transposed is not being discussed here, as we hope to report some other examples of this abnormality.

As in many cases with a single ventricle, the electrocardiogram appeared to show right ventricular preponderance.

\section{REFERENCES}

Abbott, M. E. (1936). Atlas of Congenital Heart Disease. New York.

Bembenista, J. K. (1946). Amer. Heart J., 32, 394.

Brown, J. W. (1950). Congenital Heart Disease. Staples Press, London.

Campbell, M., and Gardner, F. (1950). Brit. Heart J., 12, 184.

Evans, P. R. (1950). Brit. Heart J., 12, 258.

Kugel, M. A. (1932). Amer. Heart J., 8, 280.

Michelson, R. P. (1943). Amer. Heart J., 25, 112.

Nelson, R. L., and Wells, A. H. (1948). Minnesota Med., 31, 660.

Popjak, G. (1942). J. Path. Bact., 54, 67.

Rossman, J. I. (1942). Amer. J. Clin. Path., 12, 534.

Shechter, F. R., and Meranze, D. R. (1944). J. Pediat., 25, 150.

Taussig, H. B. (1947). Congenital Malformations of the Heart. The Commonwealth Fund, New York. 